\title{
Distribution and assessment of heavy metals in the surface sediment of Yellow River, China
}

\author{
Nan Yan, Wenbin Liu*, Huiting Xie, Lirong Gao, Ying Han, Mengjing Wang, Haifeng Li \\ State Key Laboratory of Environmental Chemistry and Ecotoxicology, Research Center for Eco-Environmental Sciences, Chinese Academy of \\ Sciences, Beijing 100085, China. E-mail: queenayan@yeah.net
}

\section{A R T I C L E I N F O}

Article history:

Received 31 July 2015

Revised 28 October 2015

Accepted 29 October 2015

Available online 29 December 2015

Keywords:

Single factor index

Nemerow pollution index

Potential ecological risk index

Heavy metal pollution

Surface sediment

\begin{abstract}
A B S T R A C T
Large amounts of heavy metals discharged by industrial cities that are located along the middle reach of Yellow River, China have detrimental impacts on both the ecological environment and human health. In this study, fourteen surface sediment samples were taken in the middle reach of the Yellow River. Contents of $\mathrm{Zn}, \mathrm{Pb}, \mathrm{Ni}, \mathrm{Cu}, \mathrm{Cr}, \mathrm{Cd}$, As were measured, and the pollution status was assessed using three widely used pollution assessment methods, including the single factor index method, Nemerow pollution index method and potential ecological risk index. The concentrations of the studied heavy metals followed the order: $\mathrm{Zn}>\mathrm{Cr}>\mathrm{Cu}>\mathrm{Ni}>\mathrm{Pb}>\mathrm{As}>\mathrm{Cd}$. Nearly $50 \%$ of sites had $\mathrm{Cu}$ and $\mathrm{Cr}$ accumulation. The concentration of $\mathrm{Cu}$ at the Yiluo River exceeded the secondary standard value of the Environmental quality standard for soils. Comparison of heavy metal concentrations between this study and other selected rivers indicated that $\mathrm{Cu}$ and $\mathrm{Cr}$ may be the major pollutants in our case. The single factor index indicated that many samples were at high levels of pollution for $\mathrm{Cu}$ and $\mathrm{Cd}$; the Nemerow pollution index indicated that the Yihe River, Luohe River, Yiluo River and Huayuankou were polluted. According to the results of potential ecological risk assessment, Cd in the tributaries of Luo River, Yihe River, and Yiluo River showed high risk toward the ecosystem and human health, Cd in Huanyuankou and $\mathrm{Cu}$ in Yiluo River showed a middle level of risk and other samples were at a low level of risk.

(c) 2015 The Research Center for Eco-Environmental Sciences, Chinese Academy of Sciences.
\end{abstract} Published by Elsevier B.V.

\section{Introduction}

Due to their characteristics of toxicity, easy bio-accumulation and non-degradation, heavy metals are considered to be serious pollutants in the environment (Bozkurt et al., 2000). Once heavy metals accumulate in the bodies of aquatic organisms and then enter the human food chain, they are difficult to degrade or excrete by organisms and humans. In addition, excessive heavy metals may have negative impacts on the growth of organisms and may interfere with the physiological functions of the human body (Deniseger et al.,
1990). Therefore, heavy metals could pose potential risks to humans and organisms. Together with the heavy metals from natural sources, a great deal of heavy metals from anthropogenic sources has been carried into the aquatic environment. The main anthropogenic sources include industrial and urban discharge, agricultural activities, and atmospheric deposition. The heavy metals in natural water could undergo some physical and chemical processes affecting their speciation, such as sorption, precipitation and complexation (Islam et al., 2015), and then settle down and be deposited in the sediments.

\footnotetext{
* Corresponding author. E-mail: liuwb@rcees.ac.cn (Wenbin Liu).
} 
Sediment is the primary sink for various heavy metals and could also act as a source of heavy metals in aquatic systems (Adams et al., 1992; Rowlatt and Lovell, 1994). It shows relative stability over space and time, which makes more consistent assessment of heavy metal pollution possible (Pekey, 2006; Tuncer et al., 2001). Thus, sediment could be an effective indicator to evaluate the pollution conditions and find the causes of pollutants.

The Yellow River is the second longest river in China with a length of $5464 \mathrm{~km}$. The basin area and the average discharge are $752,443 \mathrm{~km}^{2}$ and $2571 \mathrm{~m}^{3} / \mathrm{s}$, respectively. Because of the large amount of sand and mud, the Yellow River is the most sediment-laden river in the world (Yue et al., 2014). The middle reaches of the river flow between Hekou Town in Inner Mongolia and Zhengzhou, Henan. There are 30 large tributaries along the middle reaches, which increase the water flow by $43 \%$ at this stage. The middle reaches also contribute $92 \%$ of the river silts. Large amounts of sediment contain heavy metals, nutrients, minerals and organic matters (Milliman and Meade, 1983; Lin et al., 2016). The length of the stream passing through northern Henan is $711 \mathrm{~km}$, and eight cities are located along this distance. The Yellow River has served as a major source of water for domestic, industrial and agricultural activities in these cities. After decades of rapid population growth and booming industrialization, a large amount of heavy metals has been discharged into the river, which has a detrimental impact on both the ecological environment and human health in the long run.

Therefore, the objective of the current study was to obtain a better understanding of the distribution of the main heavy metals in the sediments of the Yellow River and to assess the risks posed by the heavy metals from the Yellow River basin using the single factor index method, Nemerow pollution index method and potential ecological risk index. The main results could be used to provide a better perspective on management to control and reduce the heavy metal pollution in the middle reach of the Yellow River.

\section{Materials and methods}

\subsection{Sample collection and analysis}

The study was carried out in the middle reaches of the Yellow River, between Xiaolangdi of Luoyang and Kaifeng, Henan
Province, with the total length of $200 \mathrm{~km}$. The surface sediment samples were collected with an Ekman grab sampler from fourteen sites in this region (Fig. 1).

At each site, three to five $5 \mathrm{~cm}$ deep samples were taken and mixed evenly. Then the samples saved in prepared brown glass bottles were sent back to the laboratory within $24 \mathrm{hr}$ and frozen in order to avoid contamination of the samples. Geographical information of the samples was recorded by the Global Positioning System (GPS) (Table 1).

All the collected samples were freeze-dried, crushed, and then sieved through a 100-mesh sieve. Approximately $0.5 \mathrm{~g}$ dried surface sediment samples were digested in $5 \mathrm{~mL}$ aqua regia $\left(\mathrm{HNO}_{3}: \mathrm{HCl}=1: 3\right)$ and heated at $140^{\circ} \mathrm{C}$ until the samples turned grey. Then $3 \mathrm{~mL} \mathrm{HClO}_{4}$ was added into the cooled samples (Qiao et al., 2011). The residues were diluted with deionized water to $25 \mathrm{~mL}$ for determining concentrations of heavy metals. Sample solutions were stored in the refrigerator at $4^{\circ} \mathrm{C}$ and then were analyzed for the main heavy metals including $\mathrm{Cr}, \mathrm{Cd}, \mathrm{Cu}, \mathrm{Pb}, \mathrm{Zn}, \mathrm{Ni}$ and $\mathrm{As}$ with an inductively coupled plasma-optical emission spectrometer (ICP-OES, Teledyne Leeman Labs, Hudson, NH, USA).

The heavy metal concentrations were the average of three repeated measurements for each sample. For quality control, reagent blanks and standard reference materials (GSS-6 soil; China National Center for Standard Material, Beijing, China) were applied.

\subsection{Pollution assessment methods}

Three methods of pollution assessment of heavy metals were conducted here, including the Single factor index method, Nemerow pollution index method, and Hakanson potential ecological risk index (Hakanson, 1980).

The single factor index method was applied to assess the pollution degree of one pollutant in the sediment samples (Chen, 2010). This method could highlight the most important pollutant which contributes most to the pollution at each site in an easy and clear way. The pollution index for a single pollutant was established according to Eq. (1):

$P_{i}=C_{i} / S_{i}$

where, $P_{i}$ is the single pollution index; $C_{i}(\mathrm{mg} / \mathrm{kg})$ represents the measured average concentration of heavy metals; $S_{i}(\mathrm{mg} / \mathrm{kg})$ is

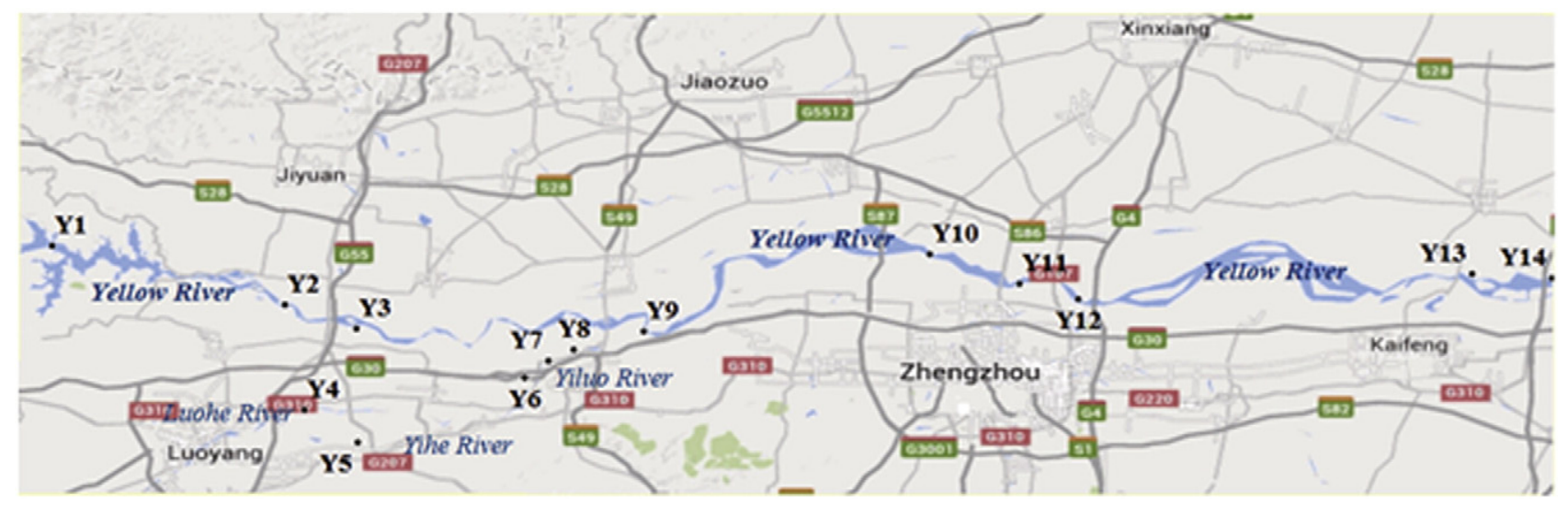

Fig. 1 - Map of the sampling sites in the middle reaches of Yellow River. 
Table 1-Geographical information of the sampling sites in the middle reaches of Yellow River.

\begin{tabular}{|c|c|c|c|}
\hline \multirow[t]{2}{*}{$\begin{array}{l}\text { Sampling } \\
\text { sites }\end{array}$} & \multirow[t]{2}{*}{ Names of sites } & \multicolumn{2}{|c|}{$\begin{array}{l}\text { Geographical } \\
\text { coordinates }\end{array}$} \\
\hline & & $\begin{array}{l}\text { North } \\
\text { latitude }\end{array}$ & $\begin{array}{c}\text { East } \\
\text { longitude }\end{array}$ \\
\hline Y1 & Xiaolangdi & 35.1311 & 112.605 \\
\hline Y2 & Luoyang Yellow River bridge 1\# & 34.8667 & 112.875 \\
\hline Y3 & Luoyang Yellow River bridge 2\# & 35.0058 & 112.7447 \\
\hline Y4 & Tributary of Luohe River & 34.7103 & 112.6708 \\
\hline Y5 & Yihe River Bridge & 34.6908 & 112.8286 \\
\hline Y6 & Yiluo River 3\# & 35.0619 & 113.1683 \\
\hline Y7 & Yiluo River 2\# & 34.8378 & 113.0624 \\
\hline Y8 & Yiluo River 1\# & 34.8471 & 113.0728 \\
\hline Y9 & $\begin{array}{l}\text { River junction of Yiluo River } \\
\text { and Yellow River }\end{array}$ & 34.9133 & 113.2039 \\
\hline Y10 & Wu Hui Yellow River bridge & 35.0144 & 113.7244 \\
\hline Y11 & Huayuankou 1\# & 34.9394 & 113.7475 \\
\hline Y12 & Huayuankou 2\# & 34.9094 & 113.6746 \\
\hline Y13 & Kaifeng Yellow River bridge 1\# & 34.9781 & 114.3731 \\
\hline Y14 & Kaifeng Yellow River bridge 2\# & 35.0444 & 114.4156 \\
\hline
\end{tabular}

the standard value of the pollutants. In this study, we used the background value of soil in Henan Province as the standard value.

The Nemerow pollution index was used to evaluate the comprehensive pollution status of sediments with all the heavy metals (Chen, 2010). Since different heavy metals may have impacts on one site, this method could provide a reasonable interpretation of the heavy metal pollution at each site as a whole. The Nemerow pollution index can be calculated by Eq. (2):

$P_{\mathrm{N}}=\sqrt{\left(\overline{P_{i}^{2}}+P_{i(\max )}^{2}\right) / 2}$

where $P_{N}$ is Nemerow pollution index; $\overline{P_{i}}$ is the arithmetic mean of the pollution index of all the pollutants; $P_{i(\max )}$ is the maximum pollution index among the pollutants, based on the single pollution index at each site.

The potential ecological risk index, which was introduced originally by Hakanson (1980), could be used to evaluate the ecological risk by considering the toxicity of the pollutant and a comparison between the concentration of the pollutant and the background value. The method has been widely applied in the assessment of heavy metal pollution in surface sediment. The potential ecological risk index (RI) was defined as following Eq. (3) (Li et al., 2013):

$\mathrm{RI}=\sum_{i=1}^{m} E_{\mathrm{r}}^{i}=\sum_{i=1}^{m}\left(\mathrm{~T}_{\mathrm{r}}^{\mathrm{i}} \times \frac{\mathrm{C}_{\mathrm{D}}^{\mathrm{i}}}{\mathrm{C}_{\mathrm{B}}^{i}}\right)$

where, $C_{D}^{i}$ and $C_{B}^{i}$ are the heavy metal concentrations measured in the sediment samples and the background values of metals in the soil, respectively. $T_{r}^{i}$ is the biological toxicity factor for a given substance. $T_{r}^{i}$ values for the metals in this study are as follows: $\mathrm{Cd}=30, \mathrm{As}=10, \mathrm{Cu}=\mathrm{Ni}=\mathrm{Pb}=5$, $\mathrm{Cr}=2$ and $\mathrm{Zn}=1$ (Hakanson, 1980; $\mathrm{Xu}$ et al., 2008). $E_{\mathrm{r}}^{\mathrm{i}}$ is the monomial potential ecological risk factor.
The classification of pollution degree of $P_{i}$ and $P_{N}$ (Chen, 2010), and the relations between $E_{r}^{i}, R I$ and their corresponding pollution degree are listed in Table 2.

\section{Results and discussion}

\subsection{Heavy metal concentrations in sediments}

The concentrations of all the seven heavy metals in each sampling site are shown in Fig. 2.

The concentrations of heavy metals in the different sites showed a wide variation. The concentration ranges of the heavy metals were: $\mathrm{Zn}, 41.8-114 \mathrm{mg} / \mathrm{kg} ; \mathrm{Pb}, 4.27-42.5 \mathrm{mg} / \mathrm{kg}$; $\mathrm{Ni}, 15.0-39.6 \mathrm{mg} / \mathrm{kg}$; Cu, 6.99-261 mg/kg; Cr, 42.6-132 mg/kg; Cd, ND-0.252 mg/kg; and As, ND-8.67 mg/kg, respectively. The average metal concentrations and the standard deviation values in the samples were: $\mathrm{Zn}, 68.4 \pm 23.5 \mathrm{mg} / \mathrm{kg}$; $\mathrm{Pb}, 15.2 \pm$ $12.8 \mathrm{mg} / \mathrm{kg} ; \mathrm{Ni}, 23.6 \pm 7.01 \mathrm{mg} / \mathrm{kg} ; \mathrm{Cu}, 40.7 \pm 66.1 \mathrm{mg} / \mathrm{kg} ; \mathrm{Cr}$, $62.4 \pm 22.8 \mathrm{mg} / \mathrm{kg} ; \mathrm{Cd}, 0.085 \pm 0.092 \mathrm{mg} / \mathrm{kg} ;$ and As, $2.46 \pm$ $2.70 \mathrm{mg} / \mathrm{kg}$, respectively, ranking in decreasing order as follows, $\mathrm{Zn}>\mathrm{Cr}>\mathrm{Cu}>\mathrm{Ni}>\mathrm{Pb}>\mathrm{As}>\mathrm{Cd}$.

Since little criteria on heavy metals in stream sediments exist nowadays, in this study, we compared the heavy metal concentrations in surface sediment samples with the mean values of national stream sediments (given as NV) (Tan et al., 2014; Yan et al., 1995), the highest background values of sediments before global industrialization (given as GV) (Hakanson, 1980), the primary standard values (given as PS) and the secondary standard values (given as SS) of the soil. PS and SS are from the Environmental quality standard for soils. The results of comparison are illustrated in Fig. 2.

All of the heavy metals had accumulated to different extents, with the exception of As. Nearly $50 \%$ of sites showed $\mathrm{Cu}$ and $\mathrm{Cr}$ accumulation. The enrichment factors of $\mathrm{Cu}$ and $\mathrm{Cr}$ were in the range of $1.12-12.4$ and 1.09-2.28, respectively, suggesting that $\mathrm{Cu}$ and $\mathrm{Cr}$ are the two main metals that could have detrimental impacts on the riverine ecosystem. In addition, the $\mathrm{Cu}$ concentrations at sites Y8, Y10, and $\mathrm{Cr}$ concentration at site Y12 were higher than the corresponding $\mathrm{GV}$ values $(50 \mathrm{mg} / \mathrm{kg}$ and $90 \mathrm{mg} / \mathrm{kg}$ ). Heavy metals mainly accumulated in the section from Y4 to Y7, namely the Yihe River, Luohe River and Yiluo River; and from Y10 to Y12, namely the Wuhui float bridge and Huayuankou.

\begin{tabular}{|c|c|c|c|}
\hline Item & $\begin{array}{c}\text { Pollution } \\
\text { degree }\end{array}$ & Item & $\begin{array}{c}\text { Pollution } \\
\text { degree }\end{array}$ \\
\hline$P_{i} \leq 1$ & Clean & $P_{\mathrm{N}} \leq 1$ & Clean \\
\hline $1<P_{i} \leq 2$ & Low & $1<P_{N} \leq 2.5$ & Low \\
\hline $2<P_{i} \leq 3$ & Moderate & $2.5<P_{N} \leq 7$ & Moderate \\
\hline$P_{i}>3$ & High & $P_{\mathrm{N}}>7$ & High \\
\hline$E_{\mathrm{r}}^{i}<40$ & Low & $\mathrm{RI}<150$ & Low \\
\hline $40 \leq E_{\mathrm{r}}^{i}<80$ & Moderate & $150 \leq \mathrm{RI}<300$ & Moderate \\
\hline $80 \leq E_{r}^{i}<160$ & Moderate to high & $300 \leq \mathrm{RI}<600$ & High \\
\hline $160 \leq E_{r}^{i}<320$ & High & $\mathrm{RI} \geq 600$ & Very high \\
\hline$E_{\mathrm{r}}^{i} \geq 320$ & Very high & & \\
\hline
\end{tabular}



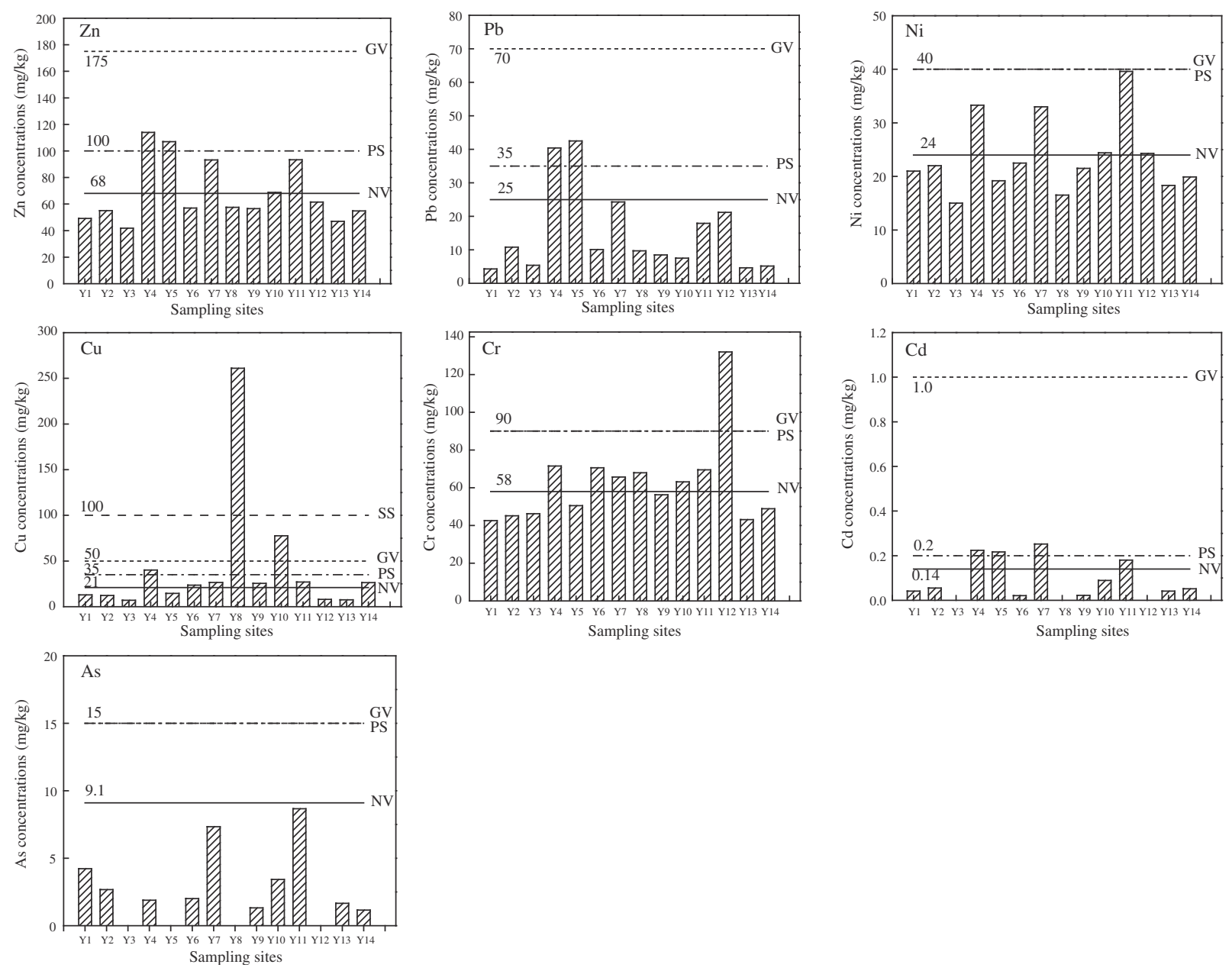

Fig. 2 - Concentrations of heavy metals in the sediments and the results of comparison. NV: the mean values of national stream sediments; GV: the highest background values of sediments before the global industrialization; PS: the primary standard values of the soil; SS: the secondary standard values of the soil.

For each heavy metal, the concentration in each sampling site was quite different. Most values did not exceed the primary standard values. However, the $\mathrm{Zn}$ concentration at sites $\mathrm{Y} 4$ and Y5, Cr concentration at site Y12, Cu concentration at sites Y4 and $\mathrm{Y} 10, \mathrm{~Pb}$ concentration at sites $\mathrm{Y} 4$ and $\mathrm{Y} 5$, and $\mathrm{Cd}$ concentration at sites Y4, Y5 and Y7 exceeded the primary standard but were under the secondary standard. Only the concentration of $\mathrm{Cu}$ at site Y8 exceeded the secondary standard value.

One of the biggest industrial cities in China is located upstream of the Yiluo River, which is Luoyang City. The industrial and domestic sewage of the city is mainly discharged into the Yihe River and Luohe River. This may be the reason that the concentrations of several heavy metals were higher than the primary standard at Luohe River (Y4) and Yihe River (Y5), and even led to the severe $\mathrm{Cu}$ pollution downstream. The results indicated that the heavy metals, which have high concentrations, have accumulated in the sediments through sedimentation and adsorption, becoming major sources of secondary pollution in the rivers.

Table 3 presents the heavy metal concentrations in sediment samples from the Yellow River and other selected rivers from the references. Comparison reveals that the concentrations of $\mathrm{Cu}$ were higher than those of other heavy metals in the South Yellow Sea, China (Yuan et al., 2012), Yellow River, China (Yuan et al., 2008), Yangtze Estuary, China (Zhang et al., 2009) and the middle reach of the Yellow River in present study. For specific heavy metals, $\mathrm{Cu}$ concentration was higher in this study than those in other studies, and $\mathrm{Cr}$ concentration was higher than that in Yellow River (Yuan et al., 2008) but lower than that in the Yangtze Estuary, China (Zhang et al., 2009). The concentrations of other heavy metals were all lower in the present study. The comparison indicated that $\mathrm{Cu}$ and $\mathrm{Cr}$ may be the major pollutants in our case, thus more attention should be paid to these heavy metals since they may have main impacts on the river sediments and in turn on organisms and humans.

\subsection{Assessment of heavy metal pollution}

The Single factor pollution index and Nemerow pollution index calculated by Eqs. (1) and (2) for the studied metals in fourteen sites are illustrated in Fig. 3.

The $P_{i}$ values of all heavy metals at sites Y1-Y3 and Y13 were less than 1 , indicating that no pollution occurred in 
Table 3 - Comparison of heavy metal concentrations in surface sediments between this study and other selected rivers from the references.

\begin{tabular}{llllllllll}
\multicolumn{1}{c}{ Location } & & $\mathrm{Zn}(\mathrm{mg} / \mathrm{kg})$ & $\mathrm{Pb}(\mathrm{mg} / \mathrm{kg})$ & $\mathrm{Ni}(\mathrm{mg} / \mathrm{kg})$ & $\mathrm{Cu}(\mathrm{mg} / \mathrm{kg})$ & $\mathrm{Cr}(\mathrm{mg} / \mathrm{kg})$ & $\mathrm{Cd}(\mathrm{mg} / \mathrm{kg})$ & As $(\mathrm{mg} / \mathrm{kg})$ & $\mathrm{Reference}$ \\
\hline Yellow River & Range & $41.8-114$ & $4.27-42.5$ & $15.0-39.6$ & $6.99-261$ & $42.6-132$ & ND-0.252 & ND-8.67 & This study \\
& Mean & $(68.4)$ & $(15.2)$ & $(23.6)$ & $(40.7)$ & $(62.4)$ & $(0.085)$ & $(2.46)$ & No \\
South Yellow Sea & Range & $24.4-244$ & $6.20-39.3$ & $\mathrm{ND}$ & $6.00-32.9$ & $\mathrm{ND}$ & $0.06-1.54$ & ND & Yuan et al. (2012) \\
& Mean & $(93.7)$ & $(17.8)$ & & $(16.9)$ & & $(0.30)$ & & \\
Yellow River & Mean & 75.66 & 21.42 & ND & 21.81 & 51.34 & 0.31 & 12.94 & Yuan et al. (2008) \\
Yangtze Estuary & Range & $47.6-154$ & $18.3-44.1$ & $17.6-48.0$ & $6.9-49.7$ & $36.9-173$ & $0.12-0.75$ & ND & Zhang et al. (2009) \\
& Mean & $(94.3)$ & $(27.3)$ & $(31.8)$ & $(30.7)$ & $(78.9)$ & $(0.261)$ & & \\
\hline
\end{tabular}

Xiaolangdi, Luoyang Yellow River and Kaifeng Yellow River. One possible reason for this is that due to the topographic features in this region, the level of industrial development is lower.

At site $\mathrm{Y} 4, \mathrm{~Pb}$ and $\mathrm{Cu}$ pollution was moderate and $\mathrm{Cd}$ reached the high pollution level, while other metals had low or no pollution. At site $\mathrm{Y} 5, \mathrm{~Pb}$ and $\mathrm{Cd}$ pollution belonged to moderate grade $\left(2<\mathrm{P}_{i} \leq 3\right)$. At site $\mathrm{Y} 6$, only $\mathrm{Cu}$ and $\mathrm{Cr}$ showed moderate pollution. The $P_{\mathrm{i}}$ value of $\mathrm{Cd}$ was 3.47 at site $\mathrm{Y} 7$, meaning Cd pollution was serious in this place, while the pollution from $\mathrm{Zn}, \mathrm{Pb}, \mathrm{Ni}, \mathrm{Cu}$ and $\mathrm{Cr}$ was low. The pollution grades of $\mathrm{Cr}$ and $\mathrm{Cu}$ were low level and high level at site $\mathrm{Y} 8$, respectively, and the $P_{i}$ values of $\mathrm{Cu}$ even reached 13.6, significantly higher than 3. Y9 was slightly polluted by $\mathrm{Cu}$. However, Y10 was severely polluted by Cu (high level) and Zn, Cr, Cd (low level). At site Y11, Cd pollution showed moderate degree and others had low pollution. Cr pollution at Site Y12 was moderate and $\mathrm{Zn}, \mathrm{Pb}$ ranked at low level. Y14 was only slightly contaminated by $\mathrm{Cu}$.

The mean pollution degree of heavy metals decreased in the order $\mathrm{Cu}>\mathrm{Cd}>\mathrm{Zn}>\mathrm{Cr}>\mathrm{Ni}>\mathrm{Pb}>\mathrm{As}$. $\mathrm{Cu}$ and $\mathrm{Cd}$ were the most important pollutants since their $P_{i}$ values were relatively higher than others at many sampling sites, reaching moderate or high pollution levels. The Single factor pollution index also has its limits, because it is more suitable for an area which is affected only by a single pollutant. The reality is that areas are always influenced by many different pollutants. Therefore, the Nemerow pollution index could be used to analyze the comprehensive pollution status in the sediments.
From the perspective of Nemerow pollution index, the pollution degree of Y8 was high level, of which the $P_{N}$ value was up to 9.77. The $P_{\mathrm{N}}$ of $\mathrm{Y} 10$ and $\mathrm{Y} 7$ were between 2.5 and 7, belonging to moderate level. Six sites ranked at low pollution level, including Y4, Y5, Y9, Y11, Y12 and Y14. No pollution was posed to the remaining sites.

The main contaminated areas were located at Yihe River (Y5), Luohe River (Y4), Yiluo River (Y6, Y7 and Y8) and Huayuankou (Y11, Y12). As mentioned above, Luoyang city, a large industrial city, is located at the upstream of the Yiluo River. This demonstrated that the anthropogenic inputs were probably the essential contributor for the pollution in these places. The sources of the heavy metals were mainly from human activities, including urbanization, industrialization, deposition of industrial wastes and the like. In addition, non-point source pollution from pesticide application in the coastal areas might also cause pollution in the river.

\subsection{Potential ecological risk assessment of heavy metals}

The potential ecological risk assessment properly combines ecological effects and toxicology. It has been widely used to assess the risks posed by heavy metals toward the ecosystem and human beings. In this study, this method was performed to analyze the heavy metal pollution status in the surface sediments of Yellow River. The calculated results of potential ecological risk from the single elements $\left(E_{\mathrm{r}}^{\mathrm{i}}\right)$ and the overall potential ecological index (RI) using Eq. (3) are presented in Table 4.
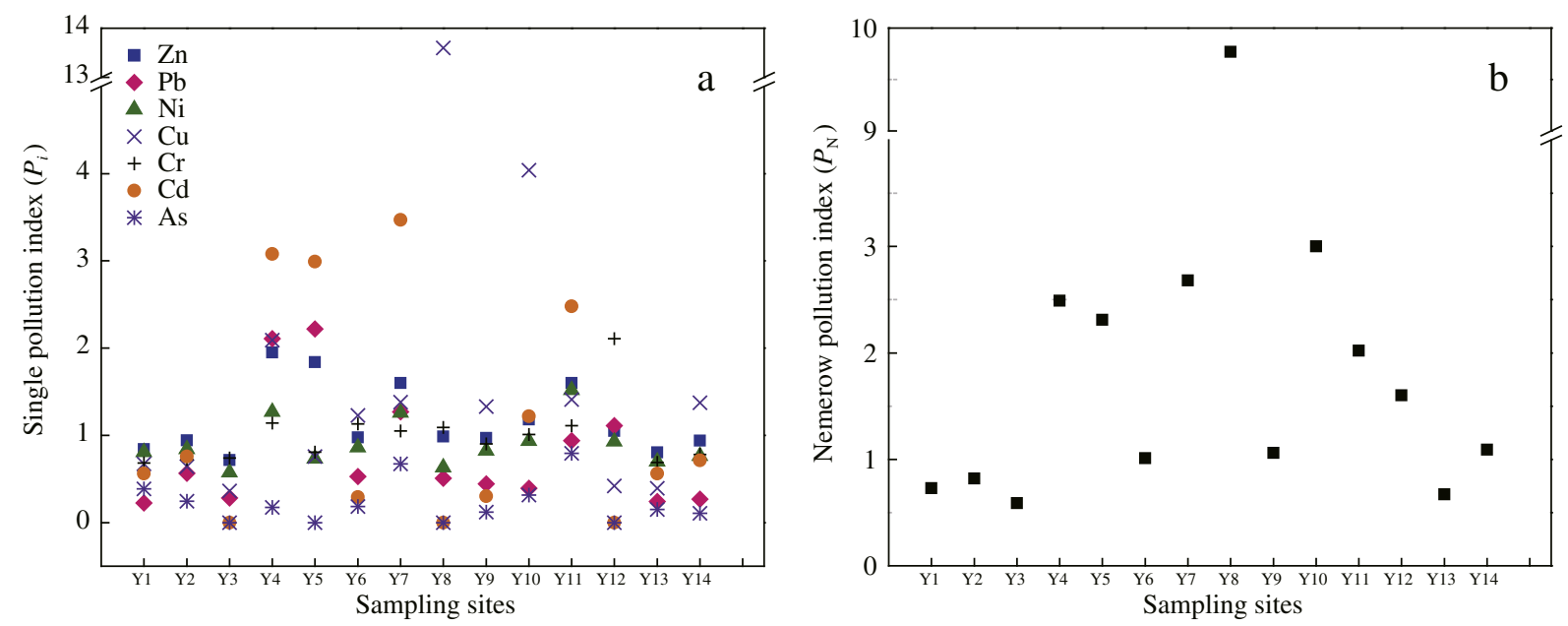

Fig. 3 - The Single pollution index (a) and Nemerow pollution index (b) of the samples. 
Table 4- $E_{\mathrm{r}}^{\mathrm{i}}$ of seven heavy metals and RI in the middle reaches of Yellow River.

\begin{tabular}{|c|c|c|c|c|c|c|c|c|}
\hline \multirow{2}{*}{ Sampling sites } & \multicolumn{7}{|c|}{$E_{r}^{i}$} & \multirow{2}{*}{ RI } \\
\hline & $\mathrm{Zn}$ & $\mathrm{Pb}$ & $\mathrm{Ni}$ & $\mathrm{Cu}$ & $\mathrm{Cr}$ & $\mathrm{Cd}$ & As & \\
\hline Y1 & 0.842 & 1.12 & 4.03 & 3.36 & 1.36 & 16.9 & 3.87 & 31.5 \\
\hline Y2 & 0.942 & 2.83 & 4.21 & 3.21 & 1.44 & 22.7 & 2.46 & 37.8 \\
\hline Y3 & 0.716 & 1.409 & 2.876 & 1.820 & 1.479 & 0.000 & 0.000 & 8.3 \\
\hline Y4 & 1.95 & 10.6 & 6.37 & 10.5 & 2.29 & 92.5 & 1.73 & 126 \\
\hline Y5 & 1.84 & 11.1 & 3.67 & 3.79 & 1.62 & 89.6 & 0.00 & 112 \\
\hline Y6 & 0.975 & 2.63 & 4.31 & 6.14 & 2.26 & 8.80 & 1.85 & 27.0 \\
\hline Y7 & 1.60 & 6.37 & 6.32 & 6.89 & 2.10 & 104 & 6.73 & 134.2 \\
\hline Y8 & 0.985 & 2.54 & 3.16 & 68.1 & 2.17 & 0.00 & 0.00 & 76.9 \\
\hline Y9 & 0.97 & 2.22 & 4.12 & 6.64 & 1.80 & 9.02 & 1.21 & 26.0 \\
\hline Y10 & 1.18 & 1.97 & 4.67 & 20.21 & 2.02 & 36.6 & 3.14 & 69.8 \\
\hline Y11 & 1.60 & 4.69 & 7.58 & 7.04 & 2.22 & 74.5 & 7.95 & 106 \\
\hline Y12 & 1.05 & 5.54 & 4.65 & 2.10 & 4.22 & 0.00 & 0.00 & 17.6 \\
\hline Y13 & 0.803 & 1.22 & 3.50 & 1.96 & 1.38 & 16.9 & 1.52 & 27.3 \\
\hline Y14 & 0.939 & 1.35 & 3.82 & 6.87 & 1.56 & 21.4 & 1.07 & 37.0 \\
\hline Mean & 1.17 & 3.97 & 4.52 & 10.6 & 2.00 & 35.2 & 2.25 & 59.7 \\
\hline
\end{tabular}

As shown in Table 4, the range of the mean $E_{\mathrm{r}}^{i}$ for each metal was from 1.17 to 35.2 , which indicated that they were all at a low degree of ecological risk. The mean $E_{\mathrm{r}}^{i}$ for seven heavy metals decreased in the order $\mathrm{Cd}>\mathrm{Cu}>\mathrm{Ni}>\mathrm{Pb}>\mathrm{As}>\mathrm{Cr}>\mathrm{Zn}$. Cd posed a relatively higher risk at sites Y4, Y5 and Y7 (89.6-104.1), reaching the third level of pollution degree $\left(80 \leq E_{\mathrm{r}}^{i}<160\right)$, and at site Y11 (74.5), it reached the moderate level $\left(40 \leq E_{\mathrm{r}}^{i}<80\right)$. The ecological risk factor $E_{\mathrm{r}}^{\mathrm{i}}$ of $\mathrm{Cu}$ at site $\mathrm{Y} 8$ was 68.1, belonging to the moderate level.

For the comprehensive potential ecological risk index (RI), the average value of all the sampling sites was 59.7, which denoted that the overall risk was at the low degree. The RI values of each site decreased in the order $\mathrm{Y} 7>\mathrm{Y} 4>\mathrm{Y} 5>\mathrm{Y} 11>\mathrm{Y} 8>\mathrm{Y} 10>$ $\mathrm{Y} 2>\mathrm{Y} 14>\mathrm{Y} 1>\mathrm{Y} 13>\mathrm{Y} 6>\mathrm{Y} 9>\mathrm{Y} 12>\mathrm{Y} 3$. Cd was the chief contributor to the RI in all the sampling sites except for $\mathrm{Y} 8$ and $\mathrm{Y12}$, in which $\mathrm{Cu}$ and $\mathrm{Pb}$ were the major contributors, respectively. Among all the sites, the RI value of Yiluo River 2\# (Y7) was 134, which almost reached the threshold value (150). Therefore, more attention should be paid to the Yiluo River, Yihe River and Luohe River because of their high risk of heavy metal pollution in the sediments.

\section{Conclusions}

In this study, the concentrations of seven heavy metals (Cr, $\mathrm{Cd}, \mathrm{Cu}, \mathrm{Pb}, \mathrm{Zn}, \mathrm{Ni}$ and $\mathrm{As}$ ) in the surface sediment samples were measured. Meanwhile, the degree of pollution and the potential risk of heavy metals in the sediment were assessed.

The mean concentrations of metals were ranked in the following sequence: $\mathrm{Zn}>\mathrm{Cr}>\mathrm{Cu}>\mathrm{Ni}>\mathrm{Pb}>\mathrm{As}>\mathrm{Cd}$. All metals were below the secondary standard at each site except for $\mathrm{Cu}$, which exceeded the secondary standard at site Yiluo River. The enrichment factors of $\mathrm{Cu}$ and $\mathrm{Cr}$, which were relatively higher than other heavy metals, indicated that these metals could create adverse effects for this river. Comparison of heavy metal concentrations between this study and other selected rivers indicated that $\mathrm{Cu}$ and $\mathrm{Cr}$ may be the major pollutants in our case. The Cu concentration at Yiluo River and $\mathrm{Cr}$ concentration at Huayuankou were over the GV values. More attention should be paid to the main polluted regions, including the Yihe River, Luohe River, Yiluo River and Huayuankou.

The single factor index of heavy metals showed that the pollution degree was decreased in the following order: $\mathrm{Cu}>\mathrm{Cd}>\mathrm{Zn}>\mathrm{Cr}>\mathrm{Ni}>\mathrm{Pb}>\mathrm{As}$. $\mathrm{Cu}$ and $\mathrm{Cd}$ had more severe pollution than others. The results of the Nemerow pollution index indicated the Yiluo River had a high pollution degree. The potential ecological risk assessment indicated that $\mathrm{Cd}$ at Yihe River, Luohe River and Yiluo River showed high ecological risk, and $\mathrm{Cd}$ at Huayuankou and $\mathrm{Cu}$ at Yiluo River showed moderate risk. The comprehensive potential ecological risk of heavy metals was found to be at low degree.

\section{Acknowledgments}

This study was supported by the National Basic Research Program (973) of China (No. 2015CB453103), the Strategic Priority Research Program of the Chinese Academy of Sciences (No. XDB14020102) and the National Natural Science Foundation of China (Nos. 21477150 and 21321004).

\section{R E F E R E N C E S}

Adams, W.J., Kimerle, R.A., Barnettt Jr., J.W., 1992. Sediment quality and aquatic life assessment. Environ. Sci. Technol. 26 (10), 1864-1875.

Bozkurt, S., Moreno, L., Neretnieks, I., 2000. Long-term processes in waste deposits. Sci. Total Environ. 250 (1-3), 101-121.

Chen, H.M., 2010. Environmental Soil Science. second ed. Science Press, Beijing.

Deniseger, J., Erickson, L.J., Austin, A., Roch, M., Clark, M.J.R., 1990. The effects of decreasing heavy metal concentrations on the biota of Buttle lake, Vancouver island, British Columbia. Water Res. 24 (4), 403-416.

Hakanson, L., 1980. An ecological risk index for aquatic pollution control. A sedimentological approach. Water Res. 14 (8), 975-1001.

Islam, M.S., Ahmed, M.K., Raknuzzaman, M., Habibullah -Al- Mamun, M., Islam, M.K., 2015. Heavy metal pollution in surface water and 
sediment: a preliminary assessment of an urban river in a developing country. Ecol. Indic. 48, 282-291.

Li, F., Huang, J.H., Zeng, G.M., Yuan, X.Z., Li, X.D., Liang, J., et al., 2013. Spatial risk assessment and sources identification of heavy metals in surface sediments from the Dongting lake, middle China. J. Geochem. Explor. 132, 75-83.

Lin, H.Y., Sun, T., Xue, S.F., Jiang, X.L., 2016. Heavy metal spatial variation, bioaccumulation, and risk assessment of Zostera japonica habitat in the Yellow River Estuary. China Sci. Total Environ. 541, 435-443.

Milliman, J.D., Meade, R.H., 1983. World-wide delivery of river sediment to the oceans. J. Geol. 91, 1-21.

Pekey, H., 2006. The distribution and sources of heavy metals in Izmit bay surface sediments affected by a polluted stream. Mar. Pollut. Bull. 52 (10), 1197-1208.

Qiao, M., Cai, C., Huang, Y.Z., Liu, Y.X., Lin, A.J., Zheng, Y.M., 2011. Characterization of soil heavy metal contamination and potential health risk in metropolitan region of northern China. Environ. Monit. Assess. 172, 353-365.

Rowlatt, S.M., Lovell, D.R., 1994. Lead, zinc and chromium in sediments around England and wales. Mar. Pollut. Bull. 28 (5), 324-329.

Tan, B., Wang, T.Y., Zhu, Z.Y., Li, Q.F., Xu, L., Lv, Y.L., 2014. Risk assessment and countermeasures of heavy metals pollution in Wanquan segment of Yanghe River. Environ. Sci. 35 (2), 719-726.
Tuncer, G., Tuncel, G., Balkas, T.I., 2001. Evolution of metal pollution in the golden horn (Turkey) sediments between 1912 and 1987. Mar. Pollut. Bull. 42 (5), 350-360.

Xu, Z.Q., Ni, S.J., Tuo, X.G., Zhang, C.J., 2008. Calculation of heavy metals' toxicity coefficient in the evaluation of potential ecological risk index. Environ. Sci. Technol. 31 (2), 112-115.

Yan, M.C., Chi, Q.H., Gu, T.X., Wang, C.S., 1995. Average element content of various sediments in China. Geophys. Geochem. Explor. 19 (6), 468-472.

Yuan, H., Wang, Y.C., Gu, S.Y., Lu, J., Zhou, H.D., Wan, X.H., 2008. Chemical forms and pollution characteristics of heavy metals in Yellow River sediments. Chin. J. Econ. 27 (11), 1966-1971.

Yuan, H.M., Song, J.M., Li, X.G., Li, N., Duan, L.Q., 2012. Distribution and contamination of heavy metals in surface sediments of the South Yellow Sea. Mar. Pollut. Bull. 64, 2151-2159.

Yue, X.L., Mu, X.M., Zhao, G.J., Shao, H.B., Gao, P., 2014. Dynamic changes of sediment load in the middle reaches of the Yellow River basin, China and implications for eco-restoration. Ecol. Eng. 73, 64-72.

Zhang, W.G., Feng, H., Chang, J.N., Qu, J.G., Xie, H.X., Yu, L.Z., 2009. Heavy metal contamination in surface sediments of Yangtze River intertidal zone: an assessment from different indexes. Environ. Pollut. 157, 1533-1543. 